\title{
NEWS
}

\section{Mixed response to Green Paper}

$\mathrm{T}$ he dental community responded in mixed fashion to the government's Green Paper Advancing our health: prevention in the 2020s.

The consultation document published by the Cabinet Office and the Department of Health and Social Care includes policies on supervised brushing in schools and water fluoridation, pledges to ban sales of energy drinks to under-16s, expansion of the sugar levy, and further action on childhood obesity.

Health Secretary Matt Hancock is facing criticism after apparently burying important proposals in the paper aimed at tackling smoking, drinking and poor diets, sparking speculation in national press that he was seeking to curry favour with incoming Prime Minister Boris Johnson, who has made clear his opposition to 'sin' taxes.

The BDA expressed its dismay at the eleventh-hour publication of the paper, described the publication as a 'fire sale', and challenged the incoming government not to turn its back on evidence-based policy making.

BDA Chair Mick Armstrong said: 'A Green Paper setting out big ideas to finally put prevention into practice now looks more like a fire sale.

'The tragedy is this document contains numerous tried-and-tested policies, which could save children from pain and our NHS millions in treatment costs.

'In the rush to avoid the charge of 'Nanny Statism' the first casualty cannot be evidence-based policymaking. Health professionals will look to the next government to show leadership, and will not let this process be swept under the carpet.'

Advocacy for tooth brushing schemes in nurseries was welcomed by the British Society of Paediatric Dentistry, while the National Community Water Fluoridation (CWF) Network welcomes the commitment that the NHS should work more closely with local authorities to implement water fluoridation schemes.

BSPD spokesperson Claire Stevens, a Consultant in Paediatric Dentistry in Greater Manchester, said 'This Green Paper represents a massive and welcome change in emphasis. It looks at the wider determinants of health and making it easier for people to make healthier choices for themselves and their families.

'Investing in oral health prevention instead of spending millions of pounds on the management of dental decay is the smart way forward and an approach which we hope the incoming Prime Minister will fully support.

'Tooth brushing schemes are an important intervention which work. Combined with getting children in to see a dentist early - a dental check by one - we are optimistic that the number of general anaesthetics for dental extractions will start to come down.

Dr Stevens said that in Greater

Manchester there were now 30,000 children in schools where there were supervised brushing schemes. An oral health promotion team had been appointed by the Greater Manchester Health and Social Care partnership and were going into schools to provide support for teachers to become oral health champions.

Simon Hearnshaw from the national CWF network praised the initiative, adding that if half the money saved on dental treatment was to be shared with local authorities, this would more than cover the costs of water fluoridation.

He added: 'Although the cost of water fluoridation is not great it nevertheless represents a financial barrier to local authorities which have so many responsibilities and limited budgets. We will be doing what we can to support councils in the most deprived areas by sharing the wealth of evidence that we have amassed on the safety and efficacy of water fluoridation.'

Alan Johnson, the former MP and Secretary of State for Health and a longtime proponent of water fluoridation commented: 'In an NHS that is truly focused on prevention and tackling the obscene health inequality statistics, Community Water Fluoridation has to be part of the strategy.

'We should not accept a situation where children are being hospitalised in droves to have their teeth removed whilst the greatest single proven solution (CWF) is not used widely enough.

'Ensuring that local authorities don't face an additional fiscal pressure as a result of fluoridation is a practical way for the NHS to be true to its founding principles by supporting local authorities like Hull and many others in the North who are determined to act on behalf of children in areas where tooth decay is most prevalent.'

The paper can be found at: www.gov.uk/ government/consultations/advancing-ourhealth-prevention-in-the-2020s 